\title{
Pengaruh senam prolanis terhadap penurunan tekanan darah pada penderita hipertensi
}

\author{
Meriem Meisyaroh Syamson ${ }^{1 *}$, Nur Fitri², Hasrul ${ }^{3}$ \\ 1,2,3 Program Studi IImu Keperawatan Stikes Muhammadiyah Sidrap, Sidenreng Rappang, Sulawesi Selatan. \\ *Email: meriemmeisyaroh90@gmail.com
}

\section{Abstract \\ Effect of prolanis gymnastics activities on blood pressure}

Background: Hypertension is a condition where systolic blood pressure is $140 \mathrm{mmHg}$ or higher and diastolic blood pressure is $90 \mathrm{mmHg}$ or higher. The factors caused such as of age, stress, obesity, heredity, unhealthy lifestyles and impaired renal function.

Purpose: To determine the effect of prolanis exercise on reducing blood pressure

Method: A quantitative study with Quasy experiment by One Group Pre-post Test Design approach. This research was conducted at the Lawawoi Community Health Center, Sidrap-Indonesia. The population was all patients with hypertension by purposive sampling.

Results: The effect of prolanic exercise on blood pressure by Wilcoxon test obtained $p$-value $=0,000$ less than $a=$ 0.05 then $\mathrm{HO}$ is rejected.

Conclusion: There is the influence of prolanic exercise on reducing blood pressure. It is recommended to medical caregiver especially in community health centre to promote the gymnastics activities for patients or vulnerable group with hypertension. By routine that activity could help to prevent or well management and medication if dont have any contra indication

\section{Keywords: Prolanis gymnastics; Blood pressure; Hypertension}

Pendahuluan: Hipertensi merupakan suatu keadaan dimana tekanan darah sistolik $140 \mathrm{mmHg}$ atau lebih tinggi dan tekanan darah diastolik $90 \mathrm{mmHg}$ atau lebih tinggi. Yang dapat mempengaruhi sistem tubuh yang lain apabila tidak ditangani disarana kesehatan yang disebabkan oleh faktor usia, stress, kegemukan, keturunan, pola konsumsi yang tidak sehat dan adanya gangguan fungsi ginjal dan untuk mengatasi hal tersebut dilakukan salah satu kegiatan berupa senam prolanis yang mampu menimbukan efek seperti beta blocker yang dapat menenangkan sistem saraf simpatikus dan melambatkan denyut jantung.

Tujuan: Untuk mengetahui pengaruh senam prolanis terhadap penurunan tekanan darah pada penderita hipertensi Metode: Penelitian kuantitatif, quasy eksperimen dengan pendekatan One Group Pre-post Test Design, dilakukan Puskesmas Lawawoi Kabupaten Sidrap. Populasinya seluruh penderita hipertensi menggunakan purposive sampling. Hasil: Pengaruh senam prolanis terhadap penurunan tekanan darah pada penderita hipertensi dengan uji Wilcoxon didapatkan nilai $p$-value $=0,000$ lebih kecil dari $\alpha=0.05$ maka $\mathrm{H} 0$ ditolak.

Simpulan: Ada pengaruh senam prolanis terhadap penurunan tekanan darah pada penderita hipertensi. Disarankan pada petugas kesehatan di puskesmas setempat untuk mempromosikan kegiatan senam untuk pasien atau kelompok rentan dengan hipertensi. Secara rutin kegiatan itu dapat membantu mencegah atau manajemen dan pengobatan yang baik jika tidak memiliki kontra indikasi.

\section{Kata Kunci: Senam prolanis; Tekanan darah; Hipertensi}

\section{PENDAHULUAN}

Menurut World Health Organization (WHO) saat ini penderita hipertensi di dunia mencapai sekitar 970 juta penderita, sekitar 330 juta terdapat di negara maju dan 640 terdapat di Negara berkembang. Di Amerika Serikat hipertensi merupakan diagnosa primer yang umum karena menyerang hampir 50 juta penduduk dimana sekitar $69 \%$ orang dewasa yang telah melewati 18 tahun sadar akan hipertensi yang mereka derita dan $58 \%$ dari mereka dirawat, tetapi hanya $31 \%$ yang terkontrol. Prevalensi hipertensi di benua Amerika lebih rendah dibandingkan di benua Eropa, dimana prevalensi hipertensi di Amerika Serikat 20,3\% dan Kanada 21,4\% sedangkan di beberapa Negara Eropa seperti Swedia 38,4\%, Italia 37,7\%, Inggris $29,6 \%$, Spanyol $40 \%$ dan Jerman $55,3 \%$ 
Pengaruh senam prolanis terhadap penurunan tekanan darah pada penderita hipertensi

(World Health Organization, 2015; American Heart Association, 2015).

Penyakit tidak menular yang menjadi perhatian dikesehatan dunia adalah penyakit hipertensi. dimana dari hasil penelitian menurut (WHO), tekanan darah yang normal bagi orang dewasa adalah 120/80 mmHg. Dimana tekanan darah sistolik yaitu $120-139 \mathrm{mmHg}$ dan tekanan darah diastolik $80-89 \mathrm{mmHg}$, dan itu juga masih bisa disebut dengan tekanan darah yang normal namun yang dikatakan hipertensi adalah apabila suatu keadaan tekanan darah sistolik $>140 \mathrm{mmHg}$ dan atau tekanan darah diastolik $>90 \mathrm{mmHg}$ (Ginting, 2018).

Indonesia sebagai salah satu negara berkembang juga tidak terlepas dari masalah kesehatan. Prevalensi nasional hipertensi saat ini adalah mencapai $29,8 \%$. Sedangkan pada data dari profil kesehatan Indonesia 2012 diketahui bahwa hipertensi merupakan salah satu penyakit yang masuk urutan ke 7 dalam 10 besar penyakit rawat inap di Rumah Sakit seluruh Indonesia yaitu mencapai 19.874 kasus yang terdiri dari 8.423 (42\%) laki-laki, 11.451 (58\%) perempuan dan 57\% terjadi pada usia lanjut (usia $>60$ tahun) (Kementerian Kesehatan Republik Indonesia, 2015).

Hipertensi atau tekanan darah tinggi dapat didefinisikan sebagai suatu keadaan dimana terjadi peningkatan dari tekanan darah didalam pembuluh arteri yang terjadi secara terus-menerus lebih dari satu periode. Hal ini terjadi bila arteriole-arteriole kontriksi. Kontriksi arteriole membuat darah sulit mengalir dan meningkatkan tekanan melawan dinding arteri. Hipertensi menambah beban kerja jantung dan arteri yang bila berlanjut dapat menimbulkan kerusakan jantung dan pembuluh darah (Udjianti, 2010).

Hipertensi adalah penyakit yang biasa dikenal dengan meningkatnya tekanan darah seseorang diatas nilai normal atau terjadi peningkatan tekanan darah yang abnormal bila tekanan darah sudah diatas $140 / 90 \mathrm{mmHg}$ maka itu sudah dianggap hipertensi untuk orang dewasa diatas 18 tahun. Hipertensi mengalami peningkatan tekanan darah sistolik dan diastolik yang tingginya sesuai dengan umur individu dan $40 \%$ yang mengalami hipertensi berusia lebih dari 65 tahun (Tarigan, Lubis, \& Syarifah, 2018).

Penderita hipertensi perlu mendapatkan perawatan yang serius dan harus ditangani dengan cepat. Salah satu faktor resiko terjadinya hipertensi adalah kandungan kolesterol darah yang tinggi atau hiperkolesterolemia. Resiko terjadinya hipertensi pada pasien hiperkolesterolemia akibat terbentuknya akumulasi plak atherosklerosis pada pembuluh darah. Hal ini karena, plak ini mempunyai komposisi kolesterol, substansi lemak yang lain, jaringan fibrosa dan kalsium (Zulkifli, 2011).

Dari data yang didapatkan, pemerintah melaksanakan program kerja yang dapat meningkatkan kualitas kesehatan masyarakat yang mengalami penyakit hipertensi. Upaya yang dilakukan dengan membuat kegiatan bernama Program Pengelolaan Penyakit Kronis (PROLANIS). Olahraga menyebabkan perubahan besar pada system sirkulasi dan pernapasan dimana keduanya berlangsung bersamaan sebagai respon homeostatic. Latihan olahraga yang sering digunakan pada penderita hipertensi adalah olahraga aerobic (Ridjab, 2005; Ginting, 2018).

Tujuan dari kegiatan senam prolanis ini adalah untuk mendorong peserta penyandang penyakit kronis terkhusus pada penyakit hipertensi untuk mencapai kualitas hidup sehat dan mencegah timbulnya komplikasi penyakit. Termasuk kepatuhan dalam menjalankan pengobatan adalah respon seseorang terhadap stimulus atau objek yang berkaitan dengan sehat- sakit, penyakit dan faktor-faktor yang mempengaruhi sehat-sakit (kesehatan). Dimana kegiatan ini bertujuan untuk menunjukkan penurunan dari tekanan darah sistolik maupun tekanan darah diastolik pada para penderita hipertensi. Kegiatan senam ini menimbulkan efek bloker yang dapat memenangkan sistem saraf simpatikus, dimana bila terjadi penurunan aktivitas simpatik pada pembuluh darah perifer dapat menjadi petunjuk penurunan tekanan darah (Purnamasari, 2017).

Hipertensi merupakan bagian dari resiko tinggi dari beberapa penyakit yang menderita penyakit jantung, tetapi juga menderita penyakit lain seperti saraf, ginjal, dan pembuluh darah. Dimana ditandai dengan peningkatan tekanan darah Sistolik sedikitnya $140 \mathrm{mmHg}$ dan tekanan darah diastolik sedikitnya $90 \mathrm{mmHg}$. Hipertensi dapat diartikan pula sebagai peningkatan tekanan darah yang abnormal dalam pembuluh darah arteri secara terus-menerus lebih dari satu periode. Pada penderita hipertensi apabila makin tinggi tekanan darah seseorang maka akan lebih besar resiko yang akan diderita (Nurarif, \& Kusuma, 2015).

\footnotetext{
Meriem Meisyaroh Syamson ${ }^{1 *}$, Nur Fitri ${ }^{2}$, Hasrul ${ }^{3}$

Program Studi llmu Keperawatan Stikes Muhammadiyah Sidrap, Sidenreng Rappang, Sulawesi Selatan.

*Email: meriemmeisyaroh90@gmail.com
} 
Pengaruh senam prolanis terhadap penurunan tekanan darah pada penderita hipertensi

Tekanan darah dipengaruhi oleh curah jantung dan tekanan perifer. Berbagai faktor yang mempengaruhi tekanan jantung dan perifer akan mempengaruhi tekanan darah seperti asupan garam yang tinggi, faktor genetik, stress dan obesitas. Selain curah jantung dan tahanan perifer sebenarnya tekanan darah dipengaruhi juga oleh tebalnya antrium kanan, tetapi tidak mempunyai banyak pengaruh. Dalam tubuh terdapat sistem yang berfungsi mencegah perubahan tekanan darah secara akut yang disebabkan oleh gangguan sirkulasi yang berusaha untuk mempertahankan kestabilan darah dalam jangka panjang (Yekti, \& Wulandari, 2011).

Meningkatnya tekanan darah di dalam arteri pada penderita hipertensi bias terjadi karena jantung memompa lebih kuat sehingga mengalirkan lebih banyak cairan pada setiap detiknya. Pembuluh darah kehilangan kelenturannya dan menjadi kaku, sehingga mereka tidak dapat mengembang pada saat jantung memompa darah melalui pembuluh darah tersebut. Karena itu, darah pada setiap denyut jantung dipaksa untuk melalui pembuluh yang sempit daripada biasanya dan menyebabkan naiknya tekanan. Inilah yang terjadi pada usia lanjut, dimana dinding pembuluh darah telah menebal dan kaku karena arteriosclerosis. Dengan cara yang sama, tekanan darah juga meningkat pada saat terjadi "Vasokontriksi", yaitu jika arteri kecil (arteriola) untuk sementara waktu mengkerut karena perangsangan saraf atau hormone di dalam darah. Terganggunya aliran darah tersebut dapat dipengaruhi oleh berbagai faktor seperti jenis kelamin, umur, dan keturunan. Selain itu, faktor lain yang berhubungan dengan perilaku atau gaya hidup adalah obesitas, kurang olahraga, kebiasaan merokok, mengkonsumsi garam berlebihan, kolestrol, alcohol, konsumsi kafein, dan stress (Haryono, \& Setianingsih, 2013).

Menurut Dinas Kesehatan di Kabupaten Sidenreng Rappang didapatkan prevalensi dari penyakit hipertensi pada tahun 2018 secara keseluruhan dengan sasaran sebanyak 27,727 penderita hipertensi, cakupannya atau yang ditemukan sebanyak 9,377 penderita hipertensi dengan presentasi $33,8 \%$ dan pada tahun 2019 pada bulan Januari sampai bulan Februari didapatkan jumlah sasaran sebanyak 18,615 penderita hipertensi, cakupannya atau yang ditemukan sebanyak 2,301 penderita hipertensi dengan presentasi $12,4 \%$ penderita hipertensi di
Kabupaten Sidrap (Dinas Kesehatan Kabupaten Sidenreng Rappang, 2019).

Di Puskesmas Lawawoi berdasarkan dari data masih banyak ditemukan kasus hipertensi, dan untuk membantu penderita salah satunya dengan kegiatan senam prolanis. Di Puskesmas itu sendiri sudah ada program senam setiap hari Selasa dan Sabtu selama 2 kali dalam seminggu, tetapi masih jarang para penderita hipertensi yang mengetahui tentang pengaruh dari kegiatan senam prolanis terhadap penurunan tekanan darah. Perlunya pemahaman dan pembuktian kepada para penderita hipertensi tentang pengaruh dari kegiatan prolanis ini sebagai salah satu bentuk penatalaksanaan dari penyakit hipertensi. Berdasarkan dari data yang didapat, peneliti tertarik untuk melakukan penelitian Bagaimana Pengaruh Senam Prolanis Terhadap Penurunan Tekanan Darah pada Penderita Hipertensi di Puskesmas Lawawoi Kabupaten Sidrap.

\section{METODE PENELITIAN}

Penelitian quasy eksperimen menggunakan pendekatan one group pre-post test design, dengan sampel menggunakan purposive sampel sebanyak 10 penderita hipertensi. Pelaksanaannya pada bulan Juni 2019, dilakukan secara bersama-sama sesuai jadwal yang disepakati di halaman Puskesmas Lawawoi Kabupaten Sidenreng Rappang. Frekuensinya dilakukan 1 kali dalam seminggu selama 1 bulan, dengan waktu 60 menit, dilaksanakan di pagi hari dan dipimpin oleh instruktur senam ahli terapis. Beberapa faktor yang tidak bisa dihindari seperti adanya responden juga yang masih menggunakan obat anti hipertensi dari resep dokter, dan diet rendah garam.

Variabel Independen (Senam Prolanis) dan variabel dependen (Tekanan Darah). Peneliti menekankan pada observasi pertama (pre-test) dengan mengukur tekanan darah masing-masing responden dengan menggunakan alat tensimeter digital, dan setelah satu bulan kemudian melakukan pengukuran tekanan darah masing-masing responden dengan menggunakan alat yang sama untuk menguji perubahan yang terjadi setelah adanya eksperimen (post-test). Selanjutnya peneliti menganalisa dengan menggunakan uji statistik untuk membandingkan hasil pengukuran Pre test dengan Post test. 
HASIL

Tabel 1. Distribusi Karakteristik Responden N =10

\begin{tabular}{lcc}
\hline Variabel & Frekuensi (f) & Persentase (\%) \\
\hline Usia & 5 & 50 \\
$55-65$ & 5 & 50 \\
$66-75$ & & \\
& & 30 \\
Jenis Kelamin & 3 & 70 \\
Laki-laki & 7 & \\
Perempuan & & \\
Pekerjaan & 7 & 10 \\
lbu Rumah Tangga & 1 & 20 \\
Karyawan & 2 & \\
Petani & & 90 \\
Pendidikan & & 10 \\
SD & 9 & \\
SMP & 1 & \\
\hline
\end{tabular}

Dapat diketahui bahwa dari 10 responden yang menderita hipertensi sebagian berumur 55-65 tahun dengan jumlah 5 orang $(50 \%)$ dan umur 66-75 tahun dengan jumlah 5 orang $(50 \%)$. Adapun terbanyak berjenis kelamin perempuan $7(70 \%)$, pekerjaan sebagai ibu rumah tangga 7 orang $(70 \%)$, dan pendidikan responden tamatan sekolah dasar SD 9 (90\%).

Tabel 2. Distribusi Responden Berdasarkan Tekanan Darah N=10

\begin{tabular}{ccccc}
\hline & \multicolumn{4}{c}{ Kelompok Responden } \\
\cline { 2 - 5 } TD & \multicolumn{3}{c}{ TD Sebelum } & \multicolumn{2}{c}{ TD Sesudah } \\
& $\begin{array}{c}\text { Frekuensi } \\
(\mathbf{f})\end{array}$ & $\begin{array}{c}\text { Persentase } \\
(\%)\end{array}$ & $\begin{array}{c}\text { Frekuensi } \\
(\mathbf{f})\end{array}$ & $\begin{array}{c}\text { Persentase } \\
(\%)\end{array}$ \\
\hline Normal & 0 & 0 & 1 & 10 \\
Ringan & 2 & 20 & 7 & 70 \\
Sedang & 7 & 70 & 2 & 20 \\
Berat & 1 & 10 & 0 & 0 \\
\hline
\end{tabular}

Berdasarkan tabel ini tekanan darah sebelum dilakukan intervensi adalah tekanan darah responden dalam nilai normal tidak ada, kategori ringan untuk tekanan darah sistolik $139-140 \mathrm{mmHg}$ dan untuk tekanan darah diastolik $\quad 80-90 \mathrm{mmHg}$ sebanyak 2 orang (20\%), kategori sedang untuk tekanan darah sistolik 150-160 mmHg dan untuk tekanan darah diastolik $90-100 \mathrm{mmHg}$ sebanyak 7 orang $(70 \%)$ dan kategori berat untuk tekanan darah sistolik $170-200 \mathrm{mmHg}$ dan untuk tekanan darah diastolik diatas $100 \mathrm{mmHg}$ sebanyak 1 orang (10\%).

Sedangkan sampel tekanan darah sesudah dilakukan intervensi adalah tekanan darah responden dalam nilai normal dengan tekanan darah sistolik 120-100 dan tekanan darah diastolik 70-80 sebanyak 1 orang (10\%), kategori ringan untuk tekanan darah sistolik $139-140 \mathrm{mmHg}$ dan untuk tekanan darah diastolik $\quad 80-90 \mathrm{mmHg}$ sebanyak 7 orang $(70 \%)$, kategori sedang untuk tekanan darah sistolik $150-160 \mathrm{mmHg}$ dan untuk tekanan darah diastolik $90-100 \mathrm{mmHg}$ sebanyak 2 orang (20\%). 
Tabel 3. Rerata Tekanan Darah Sebelum dan Setelah Dilakukan Senam Prolanis N=10

\begin{tabular}{lccccc}
\hline \multicolumn{1}{c}{ Variabel } & Frekuensi (n) & Min & Max & Mean & Stadar Deviasi \\
\hline $\begin{array}{l}\text { Rerata Tekanan Darah } \\
\begin{array}{l}\text { Sebelum Senam } \\
\text { Prolanis }\end{array}\end{array}$ & 10 & 1 & 3 & 1.90 & 0.568 \\
$\begin{array}{l}\text { Rerata Tekanan } \\
\begin{array}{l}\text { Darah Sesudah } \\
\text { Senam Prolanis }\end{array}\end{array}$ & 10 & 1 & 2 & 1.20 & 0.422 \\
\hline
\end{tabular}

Berdasarkan tabel ini menunjukan bahwa dari 10 responden didapatkan nilai rerata skor tekanan darah sebelum dilakukan intervensi sebesar 1,90 , standar deviasi 568 , dengan nilai maximum 3 dan minimum 2. Sedangkan nilai rerata skor tekanan darah setelah dilakukan intervensi sebesar 1,20, standar deviasi 422, dengan nilai maximum 2 dan minimum 1.

Tabel 4. Analisis Nilai Normalitas Rerata Pre Dan Rerata Post Pengaruh Senam Prolanis

\begin{tabular}{lccc}
\hline \multicolumn{1}{c}{ Variabel } & \multicolumn{3}{c}{ Shapiro-Wilk } \\
\cline { 2 - 4 } & Statistic & Df & p-value \\
\hline $\begin{array}{l}\text { Rerata } \\
\text { Senam }\end{array}$ & .752 & 10 & .000 \\
$\begin{array}{l}\text { Rerata TD sebelum } \\
\text { Senam }\end{array}$ & .509 & 10 & .000 \\
\hline
\end{tabular}

Berdasarkan tabel 3. menunjukan bahwa dari 10 responden uji normalitas didapatkan untuk rerata pre dan rerata post pada Shapiro-Wilk didapat nilai pre $p=0,000$ dan untuk post $p=0,000$. Dengan tingkat kemaknaan $p$ $<\alpha(0,05)$ yang dimana $p<\alpha(0,05)$ berarti uji normalitas data berdistribusi tidak normal maka dari itu dilakukan uji comperatif yaitu uji wilcoxon.

Tabel 5. Analisis Pengaruh Senam Prolanis Terhadap Penurunan Tekanan Darah

\section{N Mean Rank Sum of Ranks p-value}

\begin{tabular}{ccccc}
\hline Negative Ranks & $7^{\mathrm{a}}$ & 6.00 & 28.00 & \\
& & & & \\
Positive Ranks & $0^{\mathrm{b}}$ & 0.00 & 0,00 & 0.000 \\
Ties & $3^{\mathrm{c}}$ & & & \\
Total & 10 & & & \\
\hline
\end{tabular}

Berdasarkan tabel 5 , menunjukan bahwa dari 10 responden, hasil analisis di dapatkan nilai $p=0,000$ dengan tingkat kemaknaan $p<\alpha(0,05)$ yang dimana $0,000<0.05$ maka Ho ditolak maka dapat disimpulkan bahwa ada pengaruh Senam Prolanis Terhadap Penurunan Tekanan Darah 
Pengaruh senam prolanis terhadap penurunan tekanan darah pada penderita hipertensi

PEMBAHASAN

Perbedaan Tekanan Darah Sebelum dan Sesudah Dilakukan Senam Prolanis

Hasil penelitian menunjukkan bahwa ada perbedaan tekanan darah sebelum senam dan sesudah intervensi yang terdapat pada tabel 2 tentang senam prolanis, bahwa pelaksanaan senam prolanis ini sangat efektif dalam menurunkan tekanan darah lansia yang menderita hipertensi. Pelaksanaan senam prolanis ini beruba senam jantung sehat yang dapat menunjang kualitas hidup sehat bagi lansia untuk dapat melakukan aktivitas fisik, dimana pelaksanaan aktivitas fisik ini atau olahraga dapat menyebabkan pembuluh darah mengalami pelebaran (vasodilatasi) serta terbukanya pembuluh darah yang belum terbuka sehingga aliran darah ke sel dan jaringan meningkat.

Hipertensi primer merupakan hipertensi yang belum diketahui penyebabnya secara jelas. Berbagai faktor diduga turut berperan sebagai penyebab hipertensi primer, seperti usia, stress psikologis, pola konsumsi yang tidak sehat dan hereditas (Keturunan). Sekitar 90\% pasien hipertensi diperkirakan termasuk dalam kategori ini (Pitriani, Yanti, \& Afni, 2017). Terjadinya Hipertensi karena adanya proses degenerasi sistem sirkulasi yang dimulai dengan atherosclerosis, yakni gangguan struktur anatomi pembuluh darah perifer yang berlanjut dengan kekakuan pembuluh darah/arteri. Kekakuan pembuluh darah disertai dengan penyempitan dan kemungkinan pembesaran plaque yang menghambat gangguan peredaran darah perifer. Kekakuan dan kelembanan aliran darah menyebabkan beban jantung bertambah berat yang akhirnya dikompensasi dengan peningkatan upaya pemompaan jantung yang akan berdampak pada peningkatan tekanan darah dalam sistem sirkulasi (Bustan, 2015). Hipertensi juga merupakan salah satu penyakit degeneratif, umumnya tekanan darah bertambah secara perlahan dengan seiring bertambahnya umur (Triyanto, 2014).

Aktivitas fisik yang kurang menyebabkan tekanan darah meningkat, dengan berolahraga atau melakukan aktivitas fisik secara rutin sehingga dapat menurunkan dan menstabilkan tekanan darah. Pada penderita hipertensi respon peningkatan tekanan darah mungkin berlebihan setelah selesai aktivitas senam. Kemudian tekanan darah akan berkurang dibawah tekanan darah saat istirahat yang disebut dengan hipotensi pasca-latihan. Penurunan tekanan darah bisa berkurang 10-20 $\mathrm{mmHg}$ dan biasanya bertahan setelah latihan (Börjesson, Onerup, Lundqvist, \& Dahlöf, 2016; Hasanudin, Ardiyani, \& Perwiraningtyas, 2018).

Hasil penelitian ini serupa dengan penelitian sebelumnya yang mendapatkan perbedaan bermakna tekanan darah diastolik pada penderita hipertensi stadium sedang sebelum dan sesudah melakukan senam aerobic. Rerata yang diperoleh tekanan darah diastolik sebelum perlakuan sebesar 103,733 dan rerata tekanan darah diastolik sesudah perlakuan sebesar 99,300 (Rismayanthi, 2011).

Olahraga aerobik seperti senam jantung sehat dapat menurunkan resiko ateroskeloris dan menguatkan otot jantung dimana denyut jantung mengalami penurunan dan mengurangi kerja jantung. Hal itu bisa menurunkan tekanan darah dan mengurangi resiko aterosklerosis (Smolin, \& Grosvenor, 2016; Rahmawati, \& Aizza, 2018).

\section{Pengaruh Senam prolanis Terhadap Penurunan Tekanan Darah}

Berdasarkan tabel 4 hasil uji Wilcoxon pada tabel dijelaskan bahwa hasil analisis di dapatkan nilai $p=0,000$ dengan tingkat kemaknaan $p<\alpha$ $(0,05)$ yang dimana $0,000<0.05$ maka Ho ditolak maka dapat Simpulkan bahwa ada Pengaruh diberikan senam prolanis ini pada lansia yang menderita hipertensi dan mencegah timbulnya komplikasi penyakit. Dimana adanya penurunan dari tekanan darah sistolik maupun tekanan darah diastolik pada para penderita hipertensi, Kegiatan senam ini menimbulkan efek bloker yang dapat memenangkan sistem saraf simpatikus, dimana bila terjadi penurunan aktivitas simpatik pada pembuluh darah perifer dapat menjadi penunjang penurunan tekanan darah. Pada pelaksanaan senam jantung sehat ini terdiri dari gerakan pemanasan, inti dan gerakan pendinginan.

Gerakan pemanasan dimulai dari tundukan dan miringkan kepala,lalu bahu diangkat sambil kemudian kedua telapak tangan anda tekan dan jari-jari tangan anda tarik seperti peregangan pada umumnya. Putar tubuh kekiri dan kanan, lalu rentangkan tangan sambil kedua bahu ditarik. Tak lupa putar badan, putar sisi tubuh, dan badan dibungkukkan. Pemanasan diakhiri dengan menekuk kaki kebelakang dan menekannya secara bergantian. Kemudian gerakan inti selalu diawali

Meriem Meisyaroh Syamson ${ }^{1 *}$, Nur Fitri $^{2}$, Hasrul ${ }^{3}$

Program Studi llmu Keperawatan Stikes Muhammadiyah Sidrap, Sidenreng Rappang, Sulawesi Selatan.

*Email: meriemmeisyaroh90@gmail.com 
Pengaruh senam prolanis terhadap penurunan tekanan darah pada penderita hipertensi

gerakan inti dengan berjalan ditempat terus-menerus namun dengan gerakan tubuh atas yang bervariasi. Pertama bahu dan kepala digerak-gerakkan, lalu tangan bisa anda gerakkan dengan menggerakkan badan (tangan masih terentang). Akhir gerakan inti adalah berlari ditempat dengan gerakan bagian tubuh atas yang bisa anda variasikan. Dan selanjutnya gerakan pendinginan diawali dengan gerakan membuka kedua kaki (lebarnya selebar bahu) kemudian lanjutkan dengan membungkuk sebelum sebelum disusul dengan gerakan memutar tubuh ke kiri dan kanan. Kaki dan lengan dapat anda luruskan dan tarik sebagai gerakan akhir (Rahmawati, \& Aizza, 2018).

Hal ini sejalan dengan penelitian sebelumnya yang menunjukan bahwa senam prolanis terhadap lansia dapat mempengaruhi penurunan tekanan darah sistolik maupun diastolik, hal ini terbukti dengan didapatkan hasil analisis tekanan darah sebelum dan sesudah perlakuan yaitu nilai $p$ $=0,024$ sedangkan hasil analinis pada tekanan darah diastolik sebelum dan sesudah perlakuan didapatkan nilai $p=0,010$ yang artinya terdapat pengaruh pada tekanan darah sistolik dan diastolik responden setelah senam (Sidiq, \& Widodo, 2019).

Dengan dilakukan kegiatan senam prolanis maka respon fisiologi akan meningkatkan aliran darah keseluruh tubuh dan merelaksasikan tubuh sehingga otot-otot tubuh menjadi rileks dan meningkatkan kualitas kesehatan pada penderita hipertensi. Dengan seringnya melakukan aktivitas fisik maka kekuatan otot, tulang akan semakin membaik dan membuat aliran darah didalam tubuh penderita hipertensi pada lansia semakin lancar. dan penanganan non farmakologi dengan senam prolanis merupakan salah satu cara yang patut diperhatikan oleh lansia selain dari penanganan farmakologi sebagai salah satu upaya untuk menurunkan peningkatan tekanan darah (Hasrul, \& Muas, 2018).

Maka dengan adanya senam Prolanis terhadap penurunan tekanan darah ini dapat bermanfaat bagi lansia dalam menurunkan tekanan darah. Dipuskesmas telah menyediakan sarana pelaksanaan senam prolanis sehingga bagaimana kesadaraan dari masyarakat untuk lebih aktif dalam mengikuti senam prolanis ini demi terwujudnya taraf hidup sehat terhadap lansia yang menderita hipertensi.

\section{SIMPULAN}

Ada pengaruh Penurunan Tekanan Darah Sistolik dan Tekanan Darah Diastolik Sesudah mengikuti Senam Prolanis di Puskesmas Lawawoi Kabupaten Sidrap dengan nilai analisis $p$-value $0.000<$ a 0.05 .

\section{SARAN}

Bagi tenaga kesehatan diharapkan dapat memberikan wawasan dan pengetahuan serta informasi tentang manfaat dari melakukan senam prolanis pada penderita hipertensi. Institusi agar pihak Puskesmas Lawawoi Kabupaten Sidrap Dapat menjadikan aktivitas fisik dari senam prolanis ini sebagai suatu intervensi untuk meningkatkan kesehatan masyarakat yang datang melakukan pemeriksaan di Puskemas Lawawoi. Praktisi mengingat keterbatasan penelitian, maka pada penelitian berikutnya lebih mengembangkan penelitian ini dengan menggunakan metode yang lain dengan kelompok kontrol dan memiliki sampel yang lebih banyak sehingga validitasnya dapat dijamin.

\section{DAFTAR PUSTAKA}

American Heart Association. (2015). Hyperalertness \& Hypertension Chronic insomniacs face increased risk of high blood pressure. $\mathrm{Di}$ akses dari: http://heartinsight.heart.org/Summer-2015/Hype ralertness-Hypertension/

Börjesson, M., Onerup, A., Lundqvist, S., \& Dahlöf, B. (2016). Physical activity and exercise lower blood pressure in individuals with hypertension: narrative review of $27 \mathrm{RCTs}$. $\mathrm{Br} J$ Sports Med, 50(6), 356-361.

Bustan, M. N. (2015). Manajemen pengendalian penyakit tidak menular

$$
\begin{array}{lll}
\text { Dinas Kesehatan } & \text { Kabupaten } & \text { Sidenreng } \\
\text { Rappang.(2019). } & \text { Data dan } & \text { Informasi } \\
\text { Kesehatan Kabupaten Sidrap } &
\end{array}
$$

Ginting, J. F. (2018). Pengaruh Pengetahuan dan Sikap Penderita Hipertensi tentang Hipertensi terhadap Keaktifan dalam Kegiatan Prolanis di Puskesmas Berastagi Kabupaten Karo Tahun 2017.

\footnotetext{
Meriem Meisyaroh Syamson ${ }^{1 *}$, Nur Fitri ${ }^{2}$, Hasrul $^{3}$

Program Studi llmu Keperawatan Stikes Muhammadiyah Sidrap, Sidenreng Rappang, Sulawesi Selatan.

*Email: meriemmeisyaroh90@gmail.com
} 
Pengaruh senam prolanis terhadap penurunan tekanan darah pada penderita hipertensi

Haryono, R., \& Setianingsih, S. (2013). Awas Musuh-musuh anda setelah usia 40 tahun. Yogyakarta: Gosyen Publising

Hasanudin, H., Ardiyani, V. M., \& Perwiraningtyas, P. (2018). Hubungan aktivitas fisik dengan tekanan darah pada masyarakat penderita hipertensi di wilayah Tlogosuryo Kelurahan Tlogomas Kecamatan Lowokwaru Kota Malang. Nursing News: Jurnal IImiah Keperawatan, 3(1).

Junaidi, I. (2010). Ensiklopedia Vitamin, Mineral, dan Zat Berkhasiat Lainnya.

Hasrul, H., \& Muas, M. (2018). Pengaruh kompres hangat terhadap penurunan intensitas nyeri gout artritis pada lansia. JIKP Jurnal IImiah Kesehatan Pencerah, 7(2), 84-89

Kementerian Kesehatan Republik Indonesia. (2015). Data dan Informasi Tahun 2014 (Profil Kesehatan). Jakarta.

Nurarif, A. H., \& Kusuma, H. (2015). Aplikasi asuhan keperawatan berdasarkan diagnosa medis \& Nanda NIC-NOC. Yogyakarta: MediAction.

Pitriani, R., Yanti, J. S., \& Afni, R. (2017). Faktor-faktor yang mempengaruhi kejadian hipertensi pada lansia di wilayah kerja Puskesmas Rumbai Pesisir. Jurnal Penelitian Kesehatan" Suara Forikes"(Journal of Health Research" Forikes Voice"), 9(1), 74-77.

Purnamasari, V. D. (2017). Pengetahuan dan persepsi peserta prolanis dalam menjalani pengobatan di puskesmas. Preventia, 2(1).

Rahmawati, L., \& Aizza, N. (2018). Pengaruh senam prolanis terhadap penurunan tekanan darah pada lansia di desa Glagahwero Kecamatan Panti Kabupaten Jember. The Indonesian Journal of Health Science, 150-154.
Ridjab, D. A. (2005). Pengaruh Aktifitas Fisik Terhadap Tekanan Darah. Jurnal Kedokteran Atmajaya, 4(2), 73.

Rismayanthi, C. (2011). Penurunan Tekanan Darah pada Penderita Hipertensi Melalui Senam Aerobik Low Impact. Medikora, (1).

Sidiq, M. N., \& Widodo, A. (2019). Pengaruh Senam Prolanis terhadap Tekanan Darah Pasien Hipertensi di Puskesmas Purwodiningratan Kota Surakarta (Doctoral dissertation, Universitas Muhammadiyah Surakarta).

Smolin, L. A., \& Grosvenor, M. B. (2016). Nutrition for Sports and Exercise. Infobase Publishing.

Tarigan, A. R., Lubis, Z., \& Syarifah, S. (2018). Pengaruh pengetahuan, sikap dan dukungan keluarga terhadap diet hipertensi di desa Hulu Kecamatan Pancur Batu tahun 2016. Jurnal Kesehatan, 11(1), 9-17

Triyanto, E. (2014). Pelayanan keperawatan bagi penderita hipertensi secara terpadu. Yogyakarta: Graha IImu.

Udjianti, W. J. (2010). Keperawatan kardiovaskular.

World Health Organization. (2015). Raised blood pressure. Diakses dari: https://www.who.int/health-topics/hypertension\# tab=tab_1

Yekti, S., \& Wulandari, A. (2011). Cara jitu mengatasi hipertensi. Yogyakarta: CV Andi Offset.

Zulkifli, S. A. B. (2011). Hubungan Derajat Hipertensi Dengan Kolesterol Pada Pasien Hipertensi di RSUP Adam Malik Pada Tahun 2010. 